\title{
Estado Plurinacional: entre el nuevo proyecto y la factualidad neocolonial ${ }^{1}$
}

\author{
Pablo Mamani Ramirez² \\ Universidad Nacional Autónoma de México (UNAM) \\ Revista Willka-El Alto
}

\begin{abstract}
This article presents and discusses the deep contradictions and paradoxes that indigenous social movements face in their struggles to reverse the republican colonial order in Bolivia and to share the exercise of political power with the two hundred year old elite groups. Here the complexity is toask oneself about what type of society is being built in Bolivia. Are we moving toward a pluralist society of an Indian-popular type, toward a liberal multicultural mestizo-style society, or toward a monocultural society?
\end{abstract}

\footnotetext{
${ }^{1}$ Este trabajo forma parte de un libro de próxima publicación titulado Territorios de lucha: poder indígena y falsa descolonización en Bolivia.

${ }^{2}$ Sociólogo y Qulla aymara, Mamani Ramirez fue co-fundador de la Universidad Pública de El Alto (UPEA) y Director de la Carrera de Sociología de esa universidad. Es también fundador de la revista Willka e investigador de movimientos indígenas de Bolivia y Sud América y de los sistemas de dominación neocolonial o moderno. Es autor de varios libros y artículos, entre ellos: Wiphalas y fusiles (2012); “¿Por qué pensar fuera de los marcos de izquierda y derecha?" (2011); "El contrapoder y el poder. Lo indígena-popular y lo liberal moderno en Bolivia" (2010); "Microgobiernos barriales y su poder. Guerra del gas en El Alto-Bolivia" (2006); Geopolíticas indígenas (2005); El rugir de las multitudes y La fuerza de los levantamientos indígenas en Bolivia/Qullasuyu (2004).
} 


\section{Keywords}

Evo Morales, indigenous-originary-peasant movements, monocultural state, neo-colonial state, New Political Constitution of the State, Plurinational State, social movements

\section{Resumen}

Este trabajo expone y discute las profundas contradicciones y paradojas por las que atraviesan los movimientos sociales indios-originarios-campesinos en sus luchas por revertir el orden republicano colonial en Bolivia y compartir, con los grupos bicentenarios, el ejercicio del poder político. Aquí lo complejo es preguntarse por el tipo de sociedad que se está construyendo en Bolivia. ¿Nos encaminamos hacia una sociedad plural de tipo indio-popular, hacia una sociedad de estilo multicultural liberal mestizo, o hacia una sociedad monocultural?

\section{Palabras claves}

Estado neocolonial, Estado plurinacional, Estado monocultural, Evo Morales, movimientos indios-originarios-campesinos, movimientos sociales, Nueva Constitución Política del Estado

\section{El proyecto y la facticidad}

La aprobación de la nueva Constitución Política del Estado con una abrumadora mayoría de $61 \%$ de votos a favor, frente a $38 \%$ en contra (Corte Nacional Electoral, 2009), ${ }^{3}$ y la elección como presidente de Bolivia, por segunda vez consecutiva, de un indio, Evo Morales, con $64 \%$ de los votos, en la elección del 6 de diciembre de 2009, son, para Bolivia, las referencias de una realidad sociopolítica nueva después de casi 200 años. Lo primero se refiere a que Bolivia tiene por primera vez una constitución por la cual se define a sí misma como un "Estado plurinacional" (no hay otras experiencias políticas similares). Lo segundo es la ratificación de un "giro histórico" a favor de los pueblos y sectores sociales criminalizados durante todo este tiempo. En esto, sin embargo, hay dos hechos que urge aclarar: a) este giro histórico existe;

\footnotetext{
${ }^{3}$ Un resultado logrado el 25 de enero de 2009.
} 
pero, a la vez, existe $b$ ) una factualidad neocolonial en las instituciones públicas y gubernamentales. Nos concentraremos en esto último.

Ambos hechos implican que vivimos un proceso muy complejo, por lo que se impone construir un horizonte histórico que desmonte el neocolonialismo estatal y social de raigambre discriminatoria y racista. En este sentido, el desafío es construir instituciones públicas pluralistas y una sociedad organizada desde una lógica descolonizadora y descolonizada. El proceso boliviano es complejo, porque siendo un proceso, es, a la vez, un hecho concreto. Es una complejidad que corresponde a una etapa histórica transitoria entre el neocolonialismo y el posible devenir un horizonte de Sociedad-Estado pluralista y anti-neocolonial.

Tácitamente esto implica que lo neocolonial y neoliberal deberá dar paso a la reversibilidad histórica de la dominación, para que los pueblos y naciones indios originarios campesinos afros y populares que sufren tal hecho puedan movilizarse hacia una sociedad justa y plural. Esto significa que los grupos de "poder bicentenario", la oligarquía boliviana, deben efectivamente compartir el poder o cederlo democráticamente, y por la lucha social perderlo definitivamente frente a una realidad sociopolítica donde resurge una mayoría indio-originaria-campesina-popular ${ }^{4}$ que se autorefiere hoy como el proyecto mismo del país.

En cuanto al segundo hecho, la facticidad neocolonial es muy fuerte en relación al proyecto de un nuevo país anti-neocolonial, incluso frente a la nueva Constitución, que es un proyecto social porque tiene una visión y tiene sus formas de proceder, entre otros aspectos. La facticidad neocolonial es la realidad de la no operativización de este proyecto en el horizonte indiopopular, dado que las leyes, las normas y el manejo institucional estatal siguen haciéndose con la vieja lógica estatal (incluso igualmente liberal) y moderno-céntrica de tipo europeo. Es por ello que los postulados filosóficos y sociológicos de la pluralidad, la descolonización estatal, la democracia radical, la igualdad de hombres y mujeres y entre culturas, y fundamentalmente el espíritu de un Estado plurinacional definido en la democracia comunitaria, tienen falencias iniciales y contradicciones.

\footnotetext{
${ }^{4}$ Entendemos lo popular como los sectores urbanos o rurales que no son y no se identifican como indígenas originarios campesinos, aunque vienen de estos sectores, así el caso de mineros, fabriles, artesanos, entre otros grupos sociales dominados al igual que los indígenas originarios por los grupos de poder blancomestizo.
} 
La constatación de esto es que todavía no hay una efectividad real de políticas públicas en una lógica plural y horizontal, anti-neocolonial (como veremos más adelante). Lo prueba la Ley Electoral Transitoria (Ley 4021), aunque sea de forma coyuntural. ${ }^{5}$ Esto deja cojo de entrada al nuevo proyecto de Estado plurinacional, pues la fuente primaria, y por tanto, el argumento moral, filosófico y social de este nuevo Estado son los pueblos y naciones indias originarios campesinos. Éstos constituyen el soporte histórico del actual gobierno y del devenir social, pero en los hechos sólo tienen siete diputados, bajo la modalidad de "circunscripciones especiales", de los 130 escaños. Aunque es de reconocer que, por la vía liberal del voto y los partidos políticos o las agrupaciones ciudadanas, esta mayoría indio originaria campesina que tiene Bolivia ha logrado una gran presencia parlamentaria en las elecciones presidenciales y parlamentarias del 6 de diciembre -unas elecciones ya históricas, pero con graves límites.

Aquí nos interesa reflexionar acerca de dos situaciones concretas: a) el proyecto como tal, es decir, el Estado plurinacional como un hecho diferente e interesante frente a un Estado monocultural -aunque esté definido en la matriz liberal que se sobrepone sobre los fundamentos comunitarios indios originarios campesinos (Mamani Ramirez 2008) y b) la facticidad, o lo real de la verdad histórica, que indica que los operadores políticos y los argumentos anti-pluralidad son más fuertes que el proyecto mismo. Este es el horizonte plural del poder. Por ello sostenemos que lo neocolonial aún sigue vigente.

Si se mantiene esta situación, sería contraria a los postulados de desmontar la colonialidad del Estado; las formas de hacer política deben diferenciarse nítidamente del modelo político de enajenación del poder. En los lugares de toma de decisiones políticas y en el gobierno de Evo Morales, también entre los grupos de poder bicentenario (definidos hoy en los Comités Cívicos y hasta hace poco en la Cámara de Senadores), entre otros, se toman decisiones sin referencia social, filosófica, propositiva y sin la presencia física de los actores históricos de este proceso: los indios originarios. Se los consulta, pero no con una lógica anti-neocolonial para desmontar jerarquías y privilegios de casta, ni de forma pública participativa-decisiva. Entonces tenemos dos cuetiones en este hecho: por una parte, el proyecto está ahí como un "horizonte de realidad" posible, que sería el proceso de refundación de la

\footnotetext{
${ }^{5}$ El martes 14 de abril de 2009, frente a una multitud en la Plaza Murillo, el presidente Evo Morales se comprometió públicamente a que esto cambiará con la nueva Asamblea Plurinacional.
} 
Sociedad-Estado, y, por otro, está el proceso de hacer operativa o poner en práctica la nueva Constitución, de un modo poco acorde con la lucha indiopopular.

Ante estos hechos nos podríamos preguntar: ¿será posible que el proyecto de desmontaje de lo colonial y la realidad operativa puedan juntarse para construir efectivamente un Estado pluralista y anti-neocolonial? ¿O se repetirá la historia y los que siempre ponen los muertos en las luchas sociales se quedarán fuera de la toma de decisiones en el Estado plurinacional? Se observa que algunos políticos y autoridades gubernamentales ya actúan, como se adelantó arriba, sin los portadores de este proyecto histórico.

Este hecho nos lleva a hacer otra pregunta: ¿existen núcleos anti originarios campesinos y afros en el propio gobierno y Estado plurinacional? Si esto es así, ¿̇es apropiado hablar de un Estado plurinacional? ¿O la forma no india del actuar gubernamental es parte de una estrategia de largo aliento para que los grupos de poder bicentenario acepten la nueva realidad? También nos podríamos preguntar si este es realmente un momento fundacional para el país o es más bien una especie de "falsa descolonización" del Estado neocolonial. Finalmente, ¿̇es este el inicio de un gran proceso de desmoronamiento del Estado racista y de la sociedad construida en la lógica discriminatoria que apunta a un horizonte plurinacional e indio originario?

Partimos del supuesto de que un país plural lo construyen todos y fundamentalmente los pueblos que han sufrido el racismo en el Estado y del Estado por cerca de 200 años. Se entiende que un Estado plurinacional es diferente en su filosofía, en su teoría y en su práctica, al monoculturalismo del poder oligárquico y de las instituciones públicas liberales. Y también se entiende que, por definición, éste es un Estado anti-racista, anti-neocolonial, anti-neoliberal y anti-oligárquico, porque estaría constituido por diferentes culturas, economías, horizontes de realidad, civilizaciones y sistemas lógicos de argumentación o de pensamiento. En nuestro concepto, este es el horizonte wiphala. Está claro que el momento actual es un hecho social e histórico muy complejo, de doble dimensión histórica y esencialmente decisivo en sus múltiples sentidos. Complejo porque nos imaginamos una vida social y económica radicalmente diferente al momento actual, pero que parece tener sus primeras contradicciones. Por otra parte, es complejo porque estamos ante la posibilidad real de transformar el Estado colonial y la sociedad monocultural en un horizonte pluralista indio-popular, como se dijo antes. Los imaginarios sociales y estatales (PNUD 2007), y la realidad misma son momentos cruciales de la transformación social. 
Por lo tanto aquí es de vital importancia la implementación de una sociedad y un Estado anti-racista y capitalista. La pregunta es ¿cómo se hace operativo un Estado plurinacional y quiénes lo hacen y desde qué punto de vista filosófico y social? Para nosotros ésta es una pregunta central porque pone en marcha el desmontaje o no de lo neocolonial y de la enajenación del poder de hombres y mujeres. Este trabajo pretende tantear y pensar cuál puede ser el devenir del Estado plurinacional. En un sentido positivo, esto equivaldría, con el tiempo, al logro de lo propio sobre lo otro y, en un sentido negativo, plantearía un devenir conflictivo porque no se habrían resuelto los problemas históricos del país. Trataremos de analizar aquí, entonces, algunos de estos tópicos y las posibilidades reales de transformación del actual Estado al que llamamos el "bicentenario Estado monoculturalista" aún hoy vigente, pese a la presencia india en él.

\section{Estado plurinacional, un proyecto}

Un proyecto histórico es una construcción social largamente deseada en el horizonte ideal de un devenir de bienestar para todos los que forman parte de este planteamiento en tanto proyecto. Es un sueño colectivo racionalmente concebido para lograr algo bueno para todos y que los exprese en sus formas de ver el mundo y sus prácticas de vida. No es, entonces, una realidad sino un conjunto de hechos que deben ser puestos en práctica según los principios morales, sociales, históricos y filosóficos que lo constituyen.

Entonces, en tanto proyecto, un Estado plurinacional es parte fundamental de un "nuevo" horizonte de "realidad efectiva". Realidad efectiva quiere decir que deja de ser proyecto para convertirse en la realidad misma. Y que tiene la posibilidad de reactualizarse permanentemente, según los tiempos y las condiciones sociales de su logro o de su fracaso.

Esto lo podemos definir para el caso de un Estado plurinacional como un horizonte de realidad compartida del poder entre todos los miembros que componen ese Estado y las instituciones públicas y privadas. Sería también la realidad de un Estado descolonizado en el que las instituciones están constituidas por las diversas experiencias de gestión pública referidas a los recursos naturales y sociales, según sus horizontes culturales y prácticas sociales.

Los principios diferenciadores de un Estado plurinacional (que no solamente es la reunión de 36 nacionalidades indígenas originarias) en relación a un Estado monoculturalista o multiculturalista, es entonces la pluralidad efectiva, en particular en el ejercicio del poder y en su sistema de toma de 
decisiones, entre los diversos actores sociales y cosmovisiones. Implica, además, una nueva implementación institucional de lo estatal y privado bajo mecanismos de decisión compartida según cada realidad y, a la vez, de acuerdo a sus articulaciones horizontales.

Por otra parte, como proyecto, se haría realidad una "democracia radical" asentada en la toma de decisiones comunales y en otros sistemas de acción estatal. Queremos decir que un Estado plurinacional es una unidad compleja de los diferentes pueblos, naciones, actores, lógicas de vida social y cultural, según sus prácticas, sus formas sociales de organización social, sus economías y sistemas civilizatorios. Es decir, es un nuevo horizonte de poder plural y compartido, además del componente civilizatorio. Conceptualmente el Estado significa una organización político-territorial-administrativa, y lo plurinacional es un acto y pacto de naciones y pueblos, de clases y regiones alrededor de este Estado, pero fundamentado en la nueva Sociedad. Desde el pensamiento aymara, sería un Estado y sociedad wiphala en el que caben todos los colores y los diversos espacios de su constitución. Tal vez en este sentido el Estado plurinacional significa dejar de ser un Estado propiamente dicho. Porque lo uninacional predominante ya no es el paradigma estatal sino que éste es otro y "se abre... al juego de la combinación de distintas formas de organización, el juego en red y de entramados flexibles" (Prada 2007, 210). Es un Estado que se fundamenta en la diversidad sociológica y económica y, culturalmente, es la constitución "multiversa", como diríamos en castellano, de su realidad; es decir, constituido sobre múltiples versos o formas de ver el mundo, aunque siga siendo un Estado. Esto significa un espacio-tiempo de múltiples maneras de ser, ver, hacer y vivir el mundo. Este es el horizonte indio originario según su historia, sus luchas anticoloniales y de acuerdo a su población extensamente diseminada en todo el país.

Es un desafío histórico, porque el Estado ahora definido en lo plurinacional (y que es constitucional por el voto ciudadano) es igual a la Sociedad misma que está constituida cultural y económicamente por lo diverso y por complejas articulaciones y horizontes de realidad. Y, por lo tanto, se entiende que no es el Estado anterior, el Estado monocultural y neocolonial, sino un Estado en el que, por lo menos en el plano teórico, la Sociedad es casi igual al Estado y el Estado también es casi igual a la Sociedad. Esto puede sonar a ilusión porque no siempre puede ser así, sin embargo, su principio lógico parte de este razonamiento de ser a la vez un proceso operativo. Sumados, sale como resultado una efectividad histórica real y actual. 
Como proyecto, la cuestión es mantener la unidad, al mismo tiempo que la diversidad. Unidad no entendida en el sentido clásico del término en que sólo uno, ya sea por razón del Leviatán (la guerra) u otras, se antepone al resto para luego reclamar el respeto a este "uno", más propiamente como si este uno fuera el "todo". El desafío de mantener la unidad implica un Estado que es el continente de lo diverso y no sólo de lo antropológico (en cuanto a sus habitantes), sino fundamentalmente de lo social, cultural, político y económico. Ya que un Estado, lo sabemos muchos, es un hecho cultural, político, territorial y económico. Se diría, entonces, que el desafío como proyecto de un Estado plurinacional es el de convertirse, insistimos, en un Estado de naciones, pueblos, y actores articulados de forma horizontal y de forma abierta y respetuosa entre todos. Es la wiphala de múltiples espacios y horizontes, pero articulados al interior de las cuatro dimensiones de su espacio y tiempo. Esto es la Sociedad.

Sin duda esto posiblemente es un verdadero paradigma. Incluso un ideal que no se cumple en muchas partes del mundo "moderno" o en realidad en ninguna, pero que en el mundo indio originario de los Andes y parte de la Amazonía se ha tenido y tiene aún como ideal-práctico. Unos de los principios de este ideal-práctico es el de compartir el poder y la vida que, en términos metafóricos, en aymara o guaraní sería una gran casa: Jach'a uta o el maloca. Un hábitat articulado con sus autonomías y una totalidad autodeterminada.

Este es el proyecto real de la construcción de un horizonte de realidad efectiva anti-neocolonial, anti-republicana, anti-neoliberal y anti-racista. Estos conceptos tienen así un sentido social, histórico y estatal que, para el caso de Bolivia, expresan una profundidad insospechada porque el país fue fundado en base a los principios del colonialismo español y del racismo moderno europeo. En 1825, los indios no fundaron la "nueva" república. Pese a su gran aporte en la llamada "guerra de la independencia", han sido extraños a ella e incluso invisibilizados y vilipendiados. Los propios líderes guerrilleros, que no eran indios en las republiquetas, no han sido parte de la naciente república. De los 103 guerrilleros, sólo dos fueron parte de la Asamblea Constituyente en 1826: Miguel Lanza y José Miguel Ballivián (Arnade 2004). Y el indio no lo fue porque había sido reducido a la condición del "esclavo de la nueva república". Como tampoco en las siguientes asambleas esta matriz colonial ha cambiado; la exclusión del indio se ha convertido en la unidad fundacional o principio de la república. Una república intra muros contra los indios originarios. Por eso, la actual república es parte de esta historia colonial. La "cosa pública," que quiere decir la república, ha sido privativa de los grupos de poder de habla castellana y de cultura monoversa. De un solo verso sobre las cosas del mundo y, en particular, del Estado y las instituciones públicas. 
Propiamente, esto quiere decir que el Estado ha sido constituido por grupos minoritarios de una sola visión de mundo: la occidental europea y colonial. La plenitud de lo monocultural y civilizatorio.

Se impuso una visión cultural única que es exactamente la idea de un solo Dios universal en el mundo, frente a la pluralidad de "Otros" dioses y mundos, visiones y realidades. Y sobre esas bases, las instituciones públicas y privadas han sido definidas como espacios de "propiedad de la castas" y de sus entornos (las clases medias o grupos culturales dominantes) de legitimación social: instituciones monoculturalistas y de privilegio de poder por razón de "raza" y además auto definidida como civilizada y moderna. Es decir, el Estado monoculturalista estableció un mundo cerrado sobre sí mismo, sin referencia a otras culturas y civilizaciones, aunque en relación con ellas, las indias originarias campesinas. Por eso sostenemos que en Bolivia hay una especie de dictadura cosmológica de una sola cosmología sobre las múltiples formas de ver, sentir, vivir y hacer el mundo de la vida social y económica. Y en los últimos 200 años, el mejor lugar de esto ha sido el Estado monocivilizatorio y la Sociedad multi-civilizatoria.

En este sentido, el proyecto de un Estado plurinacional es de doble o triple dimensión. Es la posibilidad histórica de construir un nuevo sistema de gobiernos compartidos y la efectividad real de una descolonización del Estado, de plantear una radical desracialización de las instituciones públicas y una lucha en contra de la discriminación "racial", étnica, social, cultural, económica, regional o por lengua y, a la vez, una profunda descolonización territorial. Es parte de un acceso real al ejercicio de la administración del Estado, de la administración pública, y de ser parte fundamental de las fuerzas armadas y del sistema policial; en resumen, es el derecho y el hecho fáctico del compartir un poder no definido por el factor de la "raza", ni por provenir de familias oligárquicas, sino por pertenencia a pueblos, naciones, regiones, culturas, y a las capacidades formativas y habilidades de cada persona.

Esto implica, entonces, re-diseñar una institucionalidad pública diferente a la de las instituciones republicanas monoculturalistas. El sistema de gestión y administración pública es uno de los núcleos centrales de este desafío histórico, dado que, como lugar "ademocrático" del Estado (Barrios 2004, 7), se ha constituido como ajena a las formas de administrar los recursos naturales o los recursos de organización social que existen en la sociedad. La administración pública es el lugar técnico de la puesta en marcha de un tipo distinto de institucionalidad pública. La misma está constituida por una capa 
social que pertenece de uno u otro modo a la clase media blanca-mestizaurbana. Y esa ubicación que tiene en la estructura de la sociedad hace que sus integrantes desconozcan e incluso detesten las diferentes experiencias de gestión comunitaria de los recursos sociales de organización, como el de los ayllus, las comunidades (Mamani 2008c), o las capitanías y barrios urbanos (como en El Alto, Oruro, Santa Cruz, Cochabamba o Tarija).

Su racionalidad burocrática se fundamenta en el liberalismo del siglo XIX y XX. Tiene una lógica aparentemente "impersonal" de la administración del bien público o de la cosa pública, pero que en realidad se fundamenta en la lógica corporativa, patrimonial, clientelar, de círculos de poder familiar, etc. Incluso esto se constituye en el lugar central del abuso del poder y de la corrupción, como revela el caso estudiado de la administración pública en la ciudad de Santa Cruz (Jauregui y otros 2003). Ser funcionario público implica tener ciertas prerrogativas para definir los asuntos públicos sin importar otras racionalidades. Para entender esto sería de mucha importancia realizar una "etnografía del Estado". Es decir, un estudio sociológico y antropológico que descifre y haga una descripción detallada de los gustos culturales o los consumos culturales, estilos de vida, preferencia en las lecturas (no siempre ligadas a la administración sino a revistas de modelos de cuerpo y estética de tipo europeo o norteamericano), que tienen muchos funcionarios públicos. Habría que estudiar, a través de la etnografía del Estado, el tipo de conductas y acciones que éstos adoptan cuando se relacionan con los indios originarios campesinos o los afros, y los gestos y las muecas que realizan en la actividad de administrar la cosa pública, etc.

Seguramente este estudio nos develaría las profundas condiciones de practicidad neocolonial de la actual administración pública y de la sociedad, en tanto que es parte de los tejidos institucionales del Estado. De hecho, el imaginario institucional de la administración pública está lleno de imágenes que representan la monoculturalidad del Estado. Si en algún caso aparece un cuadro o una imagen de los indios, aunque es positivo, está fuera de contexto y sin referencia real a su historia. $Y$ en muchos lugares ni siquiera existe esto; revelando la factualidad de una realidad estatal profundamente ajena a la historia y a la sociedad nacional mayoritaria.

Es importante nombrar como parte sustancial del imaginario social a los medios de comunicación, que no tienen una presencia y diseño intercultural, por decir lo menos. Estos son los lugares más visibles de la monoculturalidad del poder. Incluso es así en los propios medios de comunicación del nuevo Estado plurinacional (BTV), en el momento actual, donde las entrevistas y los invitados a los debates no son propiamente los indígenas o los originarios. 
Esto sucede incluso cuando se trata de debates referidos a temas que tienen que ver con los indios originarios campesinos y con lo nacional. $Y$ en cuanto a los medios de comunicación privada (ATB, ${ }^{6}$ Red Uno, Unitel, El Deber, La Opinión, La Razón, Panamericana, Fides, etc.), éstos visibilizan de manera extraordinaria las imágenes particulares del grupo cultural y económico dominante en Bolivia. Sus presentadores, particularmente los de las "noticias", nunca son indios originarios, sino son pertenecientes a la cultura y el cuerpo dominante. Y muy pocas veces se hace referencia a la pluralidad de los sentidos de ver el mundo, de vivir y de realizar los noticieros. Ello habla del problema de la "descolonización visual".

Tal vez más que ser un noticiero, estos programas son presentaciones muy parecidas a programas publicitarios y propagandísticos. Lo neutral en ellos se presenta como la representación real del poder. Incluso se define, según varios críticos, como una visión racista y profundamente neocolonial. Así, la administración pública y los medios de comunicación son los lugares donde tampoco el horizonte plural es efectivo. Se muestran como los mayores referentes de la monoculturalidad del poder y de sus formas de administrar el bien público. Aunque en el caso de la administración pública, hay interesantes esfuerzos para cambiarla y esto constituye un gran desafío.

Otro hecho sustancial que merece estar en este horizonte de realidad descolonizante es el orden económico. En lo económico, un Estado pluralista contiene dentro de sí una diversidad de economías con sus lógicas de negocio o de hacer mercado. En efecto, la Constitución del 25 de enero de 2009 nombra cuatro tipos de economía: estatal, privada, comunal y mixta. Existe entonces la posibilidad de que estos cuatro tipos de economía tengan una relación horizontal entre sí para que ninguna en particular prime sobre el resto. Es evidente que la economía liberal tendrá siempre mayores posibilidades de imponerse sobre el resto, porque está constituida por la lógica de extracción de recursos naturales, de la sobre-ganancia y la hiperexplotación de la mano de obra. Es decir, la apropiación del excedente en manos de la empresa liberal que está siempre constituida por capitales privados. Pese a esto, la economía comunal también tiene sus propias posibilidades de constitución como una economía de gran escala sin los fundamentos de apropiación privada de los excedentes, sino dentro de lo

\footnotetext{
${ }^{6}$ Pese a que ATB es administrado por grupos cercanos al gobierno del MAS y de la Venezuela chavista.
} 
posible en la lógica de "redistribución del excedente" (Patzi 2004), que es una lógica propiamente social comunitaria. Para afirmar este hecho debemos decir que el sistema social en Bolivia se constituye, en muchos sentidos, por una lógica comunal definida en la organización de sindicatos, ayllus, capitanías (Mamani 2004), juntas vecinales, etc. En realidad pues todos de uno $u$ otro modo pertenecemos a una, dos o hasta cuatro organizaciones a la vez, hecho extraordinario que no sucede en los sistemas sociales europeos o en el norteamericano. Podríamos decir que allí los "no lugares" (Augé 2005) son los lugares sociales. Ello implica que estas sociedades se fundan en un individualismo universal secante definido por las modernas tecnologías del Internet, el celular y con referencia a los marcos culturales de estas sociedades. Mientras lo nuestro tiene otros componentes que son comunales y de igual respeto por los derechos individuales.

Construir un horizonte económico más acorde con los marcos culturales predominantes y en un sentido de bienestar social y colectivo, es el otro desafío. El sumaj kawsay o suma qamaña (en aymara y quechua suma = bien y qamaña o kawsay = vivir), literalmente, el "bien vivir", es el nuevo eje de la vida y del concepto de la "economía plural". Pues suma qamaña significa que el hombre y la mujer deben vivir una vida en equilibrio y de lucha definida en relación con: a) consigo mismo, b) la gente o la sociedad, c) la naturaleza y d) los Dioses o el Dios. Un ideal de bienestar social tal vez muy complejo pero que el mundo indio originario campesino ha construido durante más de 1000 años. Esto es tener cierta completitud entre lo material y lo espiritual (Yampara 2001). Un equilibrio deseado. Un ideal y a la vez una práctica real. Aunque en esto no hay dejar de lado el tema del conflicto, que es inherente a cualquier sociedad en el mundo.

Esto no siempre puede ser un hecho infalible, pues tiene sus propios problemas. Hay intereses individuales que se sobreponen a los comunales. Se trata, sin embargo, de apuntar a un ideal altamente social para que la economía sea parte de una vida social justa en la que no existan grandes diferencias entre los que tienen y los que no. El sistema neoliberal y el liberal produjeron una gran separación entre los grupos minoritarios de condición blanco-mestiza que tienen el poder económico frente a otros que carecen absolutamente de esto, que son los indios originarios campesinos; igual da si son minorías o mayorías. Porque ellos o ellas, viven en la indigencia, que es una degradación a una condición no humana. Por esto el proyecto es construir condiciones de igualdad económica y una efectiva igualdad jurídica entre los hombres y mujeres. Eso es lo que un proyecto debe plantear. Y su facticidad es que sea una realidad, una materialidad y también un hecho intersubjetivo. 
Implica ello construir, además, una articulación inter-subjetiva en un horizonte intercultural plural. No una interculturalidad definida desde el mismo lugar del poder como hoy todavía se define, sino desde los lugares y visiones críticas de los proyectos culturales y económicos que existen, en una relación respetuosa entre culturas y actores sociales. Pues la separación geográfica y sociocultural entre unos y otros ha producido estancos sociales que son básicamente coloniales. Y en nuestro caso, lo colonial, por el tiempo transcurrido desde la colonia, es un hecho neocolonial. Es decir, lo colonial en tanto sistema social, se ha reproducido bajo otras formas y hechos (en discursos modernos y revolucionarios) que han reproducido la matriz excluyente y segregacional. La articulación significativa de la intersubjetividad es un hecho deseable como horizonte de realidad. Significativa quiere decir que es una práctica social cotidiana y también es parte de los momentos extraordinarios de la historia social. En ambos momentos de la sociedad, se busca que la inter-subjetividad sea un hecho público y privado. Es decir, socialmente efectivo e institucionalmente normado. $Y$ ello tiene la finalidad de que unos y otros tengan las mismas posibilidades de ejercer autoridad en el Estado y en las instituciones públicas y, en la sociedad, a través de una efectiva redistribución de la economía, de la tierra y de otros recursos de vida social.

No es posible que unos tengan más dinero en el sentido concreto de la economía y accedan a una injusta redistribución de la tierra. De aquí que el otro hecho central es que la tierra sea efectivamente redistribuida, porque en la actualidad un minúsculo grupo, a través de la empresa agraria, concentra gran cantidad de tierra (Paz 2004). Esto es también un hecho que requiere una efectiva reparación histórica. Paralelamente, está también la urgencia de una reconstitución de los territorios de los ayllus y markas, como plantea el movimiento de los ayllus. Sobre esto último, el "pacto territorial", como lo llama Barrios (2008), posiblemente no es aún el hecho descolonizador de lo territorial. La cartografía territorial se organiza, por ejemplo, para los niveles de administración y de elección o designación de autoridades, en una lógica colonial-republicana, igual que la departamental, provincial y municipal. $Y$ esto de entrada habla de un gran contraste con el Estado plurinacional. Entonces, la reconstrucción de los "territorios ancestrales" y la redistribución de la tierra, son parte de un horizonte de descolonización estatal, ya que en relación a lo territorial, todo ha sido definido de forma impositiva y altamente dictatorial. Y en los tiempos de un Estado plurinacional, esto ya parece no tener sentido ni lugar. 
La cuestión, entonces, será pensar efectivamente en una nueva reorganización territorial del Estado plurinacional y en una nueva redistribución de la tierra, particularmente en el Oriente-Chaco-Amazonía. Por lo que la descolonización del Estado implica también una profunda descolonización del territorio y, a su vez, una real revolución territorial y de la tierra. Si no, ¿qué significa hablar de la descolonización del Estado si efectivamente no se descoloniza el territorio de ese Estado colonial? O más propiamente en lo territorial, significaría una "descolonización del territorio del Estado monoculturalista". Pues así lo territorial es parte de un hecho o un proyecto de lógica plural. Es decir, un Estado plural con "territorios plurales". Y la tierra es la fuente real a la que habría que llegar.

De ahí que, como está ahora planteada, la autonomía india originaria campesina es insuficiente. Hay que entender que el territorio es un diseño arbitrario (casi siempre es así en los Estados modernos y en las colonias) y, en nuestro caso, responde a una lógica de poder monocultural, uninacional y racista. Es parte del diseño del poder colonial. Ello no implica fomentar un "fundamentalismo indio", como sostiene algún ministro del Estado. ${ }^{7}$ Simplemente se trata de reparar también, al igual que los derechos civiles a la existencia, a la vida y a una cultura, el derecho al territorio ancestral. Porque el territorio es toda una cosmovisión, una vivencia de los antepasados, de los que hoy viven en él y de quienes vivirán en el tiempo futuro. Además, el territorio para nosotros es todo un sistema de pensamiento social y parte de un sistema de vida, o es la vida misma y parte de la cultura fundacional de la sociedad andina-amazónica. Es, como sostiene el presidente Evo Morales, la Madre Tierra, ${ }^{8}$ en aymara y quechua, pacha mama o mama pacha, la que deberá ser parte de un nuevo paradigma de vida humana, animal y del planeta Tierra. Las visiones anti-Estado plurinacional y anti-ambientales no deberían tener, en este sentido, mucha fuerza.

Esto quiere decir que el proyecto del Estado plurinacional es largo, profundo y también complejo. Por eso lograr el efecto de la operatividad de

\footnotetext{
${ }^{7}$ Esta fue la expresión del Ministro de Autonomías, Carlos Romero, en la presentación del libro de Franz Barrios, Hacia un Pacto territorial en Bolivia, que tuvo lugar el 2 de abril de 2009, en el Museo Nacional de Etnografía y Folklore, de la ciudad de La Paz.

${ }^{8}$ Conferencia en las Naciones Unidas sobre el Medio Ambiente realizada el 23 de abril de 2009 en Nueva York. En ella, las Naciones Unidas proclamó la celebración del Día Internacional de la Madre Tierra.
} 
este proyecto es un hecho colosalmente único. Dado que hay momentos históricos propicios que no se dan en otras circunstancias, en la vida y en la historia de las sociedades hay oportunidades únicas. Si se pasa el momento, no se dan las mismas condiciones de alianza o las posibilidades de ejercer el poder. Y ¿cuáles serían los hechos o lógicas para que lo plurinacional no sea efectivamente una realidad? Veamos esto ahora.

\section{Las prácticas y visiones no pluralistas, la facticidad}

La facticidad de las cosas del orden social dominante en Bolivia tiene, al parecer, más fuerza que el proyecto mismo, más o menos esbozado arriba. Lo fáctico quiere decir lo real. Lo que existe, la verdad de las cosas, no un proyecto. En este caso, lo real se refiere a la puesta en práctica de los principios de igualdad, pluralidad, plurinacionalidad, equidad de género, descolonización del Estado, diversidad cultural, economía plural, principios que definen al "nuevo" Estado como plurinacional. Esto definido propiamente en una Constitución que llamaríamos nosotros "pluralista". Franz Barrios (2008) Ilama a esto un "estado compuesto" porque habrá legislaciones subnacionales frente a una legislación nacional. Lo compuesto quiere decir que ya no habrá el monopolio de la legislación de la Asamblea Plurinacional, sino que existirán otras asambleas con capacidad legislativa en otros niveles de la organización territorial.

La puesta en práctica de este conjunto de principios, declaraciones y sistema de operativización, organización territorial y de los poderes estatales y sociales es el momento de la verdad práctica e histórica. No es cualquier cosa. Es el lugar y el momento fundacional, al igual que la aprobación de una Constitución. En nuestro caso, es la ejecución o la operativización de esta nueva Constitución.

O se puede decir que es el momento y el lugar de interpretación de una constitución, y esto tal vez según la pertenencia a una clase, grupo social o región, de quién la ejecuta. Pues una cosa es lo que define una constitución y otra, los principios que la hacen operativa o la ponen en práctica. En este sentido, no habría que confiarse en lo que explícitamente define una constitución. Existe la posibilidad de hacer operativos los conceptos y los principios de un modo algo distinto. Tal es la importancia de la práctica operativa para ejecutar esta Constitución. Y esto, según varios jóvenes alteños, habría que analizar crítica y detenidamente, para no ser objeto de engaño, desviación y hasta expropiación. 
En principio hay que decir que si bien la actual Constitución boliviana es pluralista, en el sentido de que contiene varios horizontes de realidad social e histórica, en ella predomina el liberalismo, o mejor dicho, estructuralmente está definida por éste, hecho que subordina lo indio originario en cuanto a su lógica comunal. En términos formales, ésta es una especie de "constitución intermedia" entre los extremos del liberalismo -fundado en el derecho de la libertad, los derechos individuales y la propiedad- y lo comunal, definido en la idea de que la sociedad es más que el individuo, que la comunidad es su valor central y que la libertad individual está dada dentro de la sociedad.

Lo plurinacional sería pues la operativización de esta Constitución intermedia. Podríamos pensar, entonces, que con esta Constitución no nos definimos ni como capitalistas ni como socialistas, sino como algo intermedio entre los dos extremos. Posiblemente esto es un hecho novedoso en nuestra historia política y social. Sin embargo, lo real de la Constitución que llamamos pluralista es que en ella predominan los principios liberales de organización estatal, económica, política, social y territorial. Aunque su novedad explícita es que ahora incorpora lo indio originario campesino como su fundamento moral, ético, simbólico, y con alguna presencia política definida en las "circunscripciones especiales", por las cuales solamente siete de las 130 diputaciones serán indígenas originarias campesinas. $Y$ el otro referente de esto son las autonomías indígenas originarias campesinas que, según lo establecido por la Ley Electoral Transitoria, serán definidas para las minorías indias originarias campesinas (el hecho es que en este espacio se supone que el sistema comunal tendría que tener mayor relevancia). Esta "mínima inclusión" se observa también en la presencia de lo indio originario campesino en el Órgano Judicial y el Órgano electoral plurinacional. De todo ello se puede decir que las minorías indias originarias van por la lógica comunal y las mayorías indias originarias van por la vía liberal. Un hecho altamente llamativo y complejo.

Las mayorías indias originarias campesinas -como los hablantes aymara, quechua y los que se identifican como tales y viven en las grandes ciudades ${ }^{9}$ y en las extensas áreas rurales- tendrán que buscar su representación por medio del sistema liberal de partidos políticos o agrupaciones ciudadanas. Es decir, bajo la forma de un ciudadano por voto, igual que como se hace hoy.

\footnotetext{
${ }^{9}$ Incluso en grandes ciudades como Buenos Aires, São Paulo, Madrid o Washington D.C.
} 
En este sistema liberal, ¿¿cuál sería la presencia de la lógica comunal en tanto sistema político propio?

Lo lógico dentro de un Estado pluralista será pensar entonces en que, dentro de un sistema liberal, lo comunal sea operativamente definido por circunscripciones uninominales y plurinominales al igual que las circunscripciones especiales, que los candidatos (hombre-mujer o mujer-hombre), sean nombrados por asambleas y otro tipo de decisión colectiva, y todo esto según las lógicas internas de cada lugar. Lo cual quiere decir que no debe haber nominaciones hechas por los candidatos a la presidencia o por los partidos políticos, como se hace hoy. Se podría recurrir al sistema político de turnos y rotaciones, y que este sistema, como experiencia de la vida social y política, esté definido en comunidades y regiones, por los ayllus y markas, por provincias, según cada lugar, y de acuerdo a sus principios de organización territorial y social. Un hecho que compensaría o hasta cierto punto revertiría el dominio liberal sobre lo indio originario comunal en el "nuevo" Estado plurinacional.

Actualmente tenemos un sistema de representación institucional muy complejo. Ahora, si continúa este sistema, pues será parte de la postergación de las demandas indias originarias campesinas y populares en el sentido de una re-fundación efectiva de un nuevo país y un nuevo sistema político. En estas condiciones cobran vital importancia las propuestas prácticas, la presencia decisiva de los actores, que han producido este proceso, dentro de las decisiones centrales, y también la necesidad de generar sistemas de acción colectiva que interpelen a los actores políticos, específicamente a ministros y parlamentarios, que negocian y deciden sin consensuar con los actores históricos.

Y la factualidad de los hechos es que se ha empezado a actuar y a definir leyes en este sentido. La Ley Electoral Transitoria hasta ahora es el ejemplo real, pero hay otras de 2009, 2010, etc. Esto sucede desde el mismo lugar del gobierno que promueve lo plurinacional; por otra parte, los grupos de poder bicentenario no consultan, consensúan, ni llevan las propuestas de los indios originarios campesinos a las instancias de definición de leyes, reglamentos, políticas públicas, etc. Aun cuando este sistema de proceder haya sido cuestionado en tanto sistema de expropiación del poder, lo curioso es que se vuelve a caminar por las mismas sendas. O mejor, es la forma política del anterior Estado monoculturalista. Ello se explica tal vez porque "Los servidores públicos como agentes de reproducción cotidiana de la razón de Estado provienen, en su gran mayoría en Bolivia, de los sectores medios relacionados con la cultura occidental, urbana, castellano hablante, que 
detentan el control de la cosa pública al margen del conjunto diverso y abigarrado de la formación social boliviana" (Eduardo Paz 2007, 6). Ciertos espacios del Estado y los ministerios, en este sentido, se sujetan a los cánones del viejo sistema político y develan su pertenencia y los intereses de una clase social o grupo social étnicamente dominante.

Así, estamos diciendo que esto es una realidad efectiva en una cosmovisión, en sus valores y principios, y en los cánones académicos de una facticidad no plural, sino monocultural y, por tanto, parte de una fragilidad (o de una contradicción) del Estado plurinacional. En éste, el simple hecho de leer libros y estudiar el mundo indio originario sin ser parte de él, habla de una distancia ontológica y de compromiso con lo plural, o con la descolonización. Es otra realidad. No se puede, por ejemplo, exigir a las autoridades políticas si no cumplen con los compromisos porque viven geográficamente alejados del mundo indio originario rural-urbano. Por ello, parece que una cosa es el discurso con el que se identifica uno, en nuestro caso, con lo indio originario, y otra es la realidad misma de las prácticas, de las lógicas de vida y los sentidos de un horizonte de realidad. Aquí estamos ante el problema de la ontología del poder. El no vivir las grandes demandas históricas, o las históricas frustraciones, o las luchas contemporáneas, es parte de este hecho. Y los estudios académicos en ello tienen su déficit. No ayudan a entender las complejidades de la secular dominación colonial. Incluso las instituciones académicas se han convertido, en cierto modo, en parte de un "colonialismo académico". Este asunto también tendría que ser parte de una mirada descolonizada, profundamente crítica.

El hecho parece ser claro. Si no se vive o no se tiene experiencia de la vida india, pues no la pueden orientar los académicos. Socialmente y en experiencia personal, éstos no han sufrido los grados de racismo y dolorosa discriminación. La sienten a distancia por un marco ideológico o político que han logrado construir (hasta incluso por ocasión) y que les informa de las condiciones de brutalidad colonial que sufre el indio originario campesino popular.

Y esto se ha convertido, o mejor, es parte, de una racionalidad estatal. Ello implica que los procedimientos cotidianos y las formas de proceder en lo público son todo un sistema de actuación estatal que funda un orden social. En este sentido, es importante analizar los "significados de las actividades, formas, rutinas y rituales del Estado para la constitución y la regulación de las identidades sociales, y en última instancia de nuestras subjetividades", como Philipp Corrigan y Derek Sayer sostienen para el caso del estudio de la formación del moderno Estado inglés $(2007,43)$. La administración pública y 
sus cánones de actuación definen un conjunto de pautas para un tipo de racionalidad, particularmente, la de los sistemas de dominación. En este sentido, las rutinas de actuación de las autoridades tienen un trasfondo real que es del tipo de Estado aún neocolonial en Bolivia.

Esto no quiere decir que los no indios deban quedar fuera del nuevo diseño institucional del Estado, o convertirse en sujetos de una "nueva" dominación india. Lo importante en una lógica pluralista es que el diseño de la nueva administración pública, la aprobación de las nuevas leyes y de reglamentos, el diseño de los sistemas de representación política en el Estado, no esté dirigido hegemónicamente por un solo sector de la sociedad: el de clase media urbana blanco-mestiza. Se entiende que un Estado plurinacional es de todos y, en este sentido, todos tienen la responsabilidad y el deber de ser parte de la nueva construcción histórica, lo cual incluso suena como un pacto. Se podría argüir contra esto que hay una efectiva participación de los indios originarios campesinos en el diseño del Estado plurinacional, lo que es cierto, pero los lugares e instancias estratégicas como el área económica, las autonomías, la producción agropecuaria e industrial, la comunicacional y la cultural, están siempre dirigidos por los no indios originarios. Incluso está el hecho de que el actual gobierno no pueda ser un gobierno plurinacional aunque mantenga algún grado de equidad de género. Esto contradice la Constitución plurinacional y constituye un desafío histórico para cambiar la lógica del ejercicio del poder.

Por ello, los debates y la implementación de lo plurinacional se hacen desde el horizonte monocultural de algunos sectores, más propiamente de lo blanco-mestizo hoy definido con discurso de izquierda. Así la paradoja es que el Estado quiere reformarse y apuesta constitucionalmente por eso, pero los operadores, las lógicas de rutina estatal, se mueven todavía dentro de los esquemas de un orden ajeno a la plurinacionalidad. Aunque hay iniciales e importantes cambios de la rutina estatal, es evidente que no son sustanciales. Esto puede observarse en algunos indios originarios urbanos que, a través de actos de corrupción, ${ }^{10}$ entre otros hechos, demuestran esa condición. Estos son los procesos iniciales para medir los parámetros y lógicas operativas de la nueva Constitución.

${ }^{10}$ Tal vez el hecho más notable es el de ex-senador Santos Ramírez, ex-presidente de YPFB, entre otros. 
Como sostienen muchos sectores, o propiamente los movimientos indios originarios, el derrotero histórico del Estado plurinacional es dejar de ser, en particular, anti-indio originario campesino. Es decir, dejar de ser neocolonial, monoculturalista y racista. Frente a esta situación, los radicales de la llamada derecha moderada y ultraderecha juegan a detener el actual proceso de la lucha social. Buscan lograr en los movimientos sociales una frustración temprana con su propio Presidente y con su "propia" Constitución. En esta lógica, algunos grupos y sectores del gobierno de Evo Morales al parecer juegan sin saberlo, o sabiéndolo, con dichas fuerzas neocoloniales y mono-civilizatorias. Un hecho que será parte de un largo debate y de una acción colectiva.

Por otra parte, está también el hecho de que los propios líderes de los movimientos sociales e incluso los actores colectivos, permiten que esto sea así. Sobre esto último, se observa que éstos parecieran confiar mucho en los conocimientos técnico-estatales y habilidades políticas de los ministros. Incluso, en el caso de la Ley Electoral Transitoria, las autoridades originarías del movimiento de los ayllus justifican o se resignan tempranamente a que su representación sea reducida en número; un hecho que contradice la lógica autoafirmativa de un "yo colectivo" propio. Seguramente con esta Ley se marca un horizonte de aceptación para que los ministros y parlamentarios actúen de este modo. Los Mallkus y T'allas parecieran con ello dejar de lado el gran proyecto histórico de la "Reconstitución territorial de los antiguos ayllus y markas" (Mamani 2008), aunque luego se firme un acuerdo entre el Ministerio de Descentralización y los mallkus para convertir a los municipios en municipios indios. Esto a diferencia de la protesta del movimiento indígena del oriente-amazonía a la cabeza de la CIDOB, que reclamaron más escaños parlamentarios. Esto muestra un momento de gran duda en la lucha social.

Es un hecho que la tri-territorialidad nacional (departamento, provincia y municipio) ratifica la mono-civilización territorial del anterior Estado. Pese a ello, la organización tri-territorial es un hecho novedoso si tomamos en cuenta los 180 años de la república, ya que se pasa de una organización territorial unitarista a una organización tri-territorial. Barrios define este tipo de organización territorial como "constitucionalmente equipolente" y lo territorial indígena como "geometría variable" (Barrios 2008). Con esto indica que los tres tipos de territorio tienen más peso y lo indio es casi subalterno, porque dependerá de cómo se lo defina. En principio la territorialidad indígena es como una TCO (Tierra Comunitaria de Origen) y luego será "autonomía indígena originaria campesina". Hoy es definida como TIOC (Territorios Indígena Originario Campesinos) o efectivamente como ente territorial con cualidad gubernativa y con capacidad legislativa. 
Entonces seguir viendo al "Otro" - el blanco-mestizo- como portador de la verdad histórica, nos habla también de cierto colonialismo interior por parte de los históricamente dominados. O sea, el creer que el "Otro" sabe todo, porque habla bien y tiene conocimientos técnicos, es mostrar este colonialismo interior que es un hecho que pertenece a la larga historia de la dominación.

Esto no quiere decir que todos compartan esta condición. A partir de una experiencia de lucha por la anti-discriminación y junto a los luchadores sociales, se aprenden las condiciones efectivas de transformación social. Esto último se observa en muchos administradores públicos que tienen una gran ansiedad de aprender, de saber, incluso de vivir el mundo indio originario campesino, de hablar su idioma y realmente de moverse en el campo de la interculturalidad crítica. Pero también está claro que otras personas están desconcertadas porque no se ubican en el nuevo contexto sociopolítico y constitucional. Luchan por argumentar y mantener el viejo sistema estatal. Más propiamente, esto se observa en varios niveles de la administración pública, entre otros lugares. Parte de una realidad compleja y de gran debate.

Este es, sin duda, un campo de luchas y disputas por revertir el orden neocolonial todavía vigente y la transformación fáctica de esta colonialidad estatal, de las reglas y normas en las relaciones sociales e institucionales. Como se observa, todo esto depende también, tal vez fundamentalmente, de las capacidades de los actores históricos para impugnar y proponer de forma técnica operativa y conceptual, un nuevo diseño estatal, o ayudar a proponer una nueva institucionalidad. Esto es valorar las propias lógicas de poder y de gestión pública que tienen los ayllus y las comunidades. Se trata entonces de un rediseño institucional del país en todos los planos y condiciones. Las experiencias de "gestión comunitaria" con las asambleas, el sistema de los turnos y las rotaciones, el control comunal de las acciones de las autoridades, el sistema político de rotaciones según los lugares y los tiempos (Mamani, 2008), son los referentes de este proyecto. Varios líderes sociales y comunarios/rias plantean que esto debería ser una facticidad, o una realidad misma. En otras palabras, una realidad institucional no enajenada, sino actuada y dirigida por estos actores sociales en un horizonte de realidad efectiva que es descolonizadora e intercultural, aunque no necesariamente lo indio originario de por sí es descolonizador. En esto también existen grandes dificultades y contradicciones.

Frente a lo dicho arriba, se tiene a los grupos del poder oligárquico, en particular los autoreferidos como "blancos". Y para estos grupos, lo 
comunal es sencillamente algo inconcebible. El sistema comunal de la política para este sector es un sistema antagónico al liberalismo, aunque aquello no sea un liberalismo propiamente dicho, sino más bien algo cercano al neocolonialismo. Para este sector, lo indio originario campesino no tiene un valor estatal ni posible de ser pensado en un horizonte de realidad política más democrática y flexible para diseñar un "nuevo" sistema de representación social y sus sistemas de operativización. Este sector concibe el poder como una relación mecánica (aunque cierta) de $A$ con $B$, donde $A$ manda sí o sí y $\mathrm{B}$ obedece sin objetar, cuando en realidad $\mathrm{B}$ puede y también es factor de poder o de contra-poder. En el pensamiento del ayllu B es el contrapeso de $\mathrm{A}$. $\mathrm{O}$ hay una relación de ida y vuelta entre $\mathrm{A}$ y $\mathrm{B}$.

Los grupos bicentenarios han sido propietarios del Estado durante casi 200 años. Se observa y se lee en las actuaciones de estos grupos un profundo rechazo a lo indio. Expresan abiertamente, no de manera simulada, su gran desconfianza en lo que puede hacer y decir el indio originario campesino. Más ahora con el Presidente Indio en función pública. Hoy ser indio crítico es lo Otro, es el peligro real que disputa el lenguaje y el proyecto. El informe del Relator Especial de Naciones Unidas (Rodolfo Stavenhagen) sobre los derechos indios es elocuente. Este informe sostiene que, en Bolivia, existe un racismo anti-indio, tanto contra el presidente Morales como contra los originarios de a pie (Stavenhagen 2009).

Algo que ha sido normal en la historia de la república y que hoy, por las nuevas condiciones sociales y políticas nacionales e internacionales ya no es un hecho aceptado, es el "racismo de élite" (Van Dijk 2003). Este racismo es la inferiorización del "Otro" bajo el argumento de su aparente inferioridad cultural, por el color de la piel, o la lengua que habla este "Otro". En nuestro caso, este racismo de élite se ha traducido en un racismo estatal, es decir, una segregación sistemática, a pesar de que después de 1952 ya no es constitucional, sino más bien social, económica, cultural y política. Las nuevas "fronteras sociales y geográfico-espaciales" nos ayudan a descubrir que se había construido una subjetividad de élite bastante interesante en el sentido de la propiedad de la administración pública y del Estado, incluso del cuerpo del Presidente, siempre de condición criollo-mestizo.

Este racismo de élite hoy es una facticidad que se opone al posible movimiento de transformación o descolonización del Estado y de los imaginarios sociales y culturales. Es decir, afecta tanto a los planos de construcción subjetiva de la representación del mundo que tiene la gente, como a los planos de la institucionalidad estatal y de las instituciones sociales. Esta es una realidad dura. Es la exposición elocuente de la misma 
neocolonialidad. Es la factualidad de la verdad histórica. No cambia, ni apuesta por cambiar. Lucha por mantener el orden cosmológico de un solo verso. O mejor, de una sola forma de ver, de sentir, representar, actuar, y decir las cosas. Aunque aparentemente se muestra como moderna, culta, liberal, en los hechos actúa con un aparatoso discurso similar al de los doctores de "dos caras" de 1825 (Arnade 2004), a través del cual el discurso es liberal y la práctica neocolonial, y que incluso funciona en la lógica endogámica (eso lo apuntamos más arriba). Esto quiere decir que la reproducción biológica y cultural se produce en los marcos de acción sólo circunscrita en sus propios círculos de poder. Y lo político funciona también en esta misma lógica. En estas condiciones es casi imposible alcanzar la pluralidad institucional y las formas de construir una realidad descolonizada y descolonizadora. El proyecto y la efectividad práctica de un Estado plurinacional es el hecho de transformar esta cruda realidad. En resumen, una realidad que está ahí. Y está ahí también el proyecto, la nueva Constitución como instrumento.

\section{Hora de operativizar el proyecto}

De lo anterior se puede resumir que el Estado plurinacional es y será parte de un profundo campo de lucha o de disputas entre los diferentes actores sociales y políticos, y los proyectos históricos que hoy están vigentes y los que nacerán, o se harán visibles. La aprobación de la nueva Constitución Política del Estado el 25 de enero de 2009 ha cerrado una puerta a esta lucha social y ha abierto a la vez otras puertas a la lucha social y política.

Estas nuevas luchas dependerán de las condiciones y propuestas operativas que la sociedad y sus organizaciones propongan al interior del Estado y, fuera de éste, en un horizonte de realidad plural. Ya se han empezado a mover de forma fáctica las primeras condiciones de esta lucha. Los bicentenarios grupos de poder, las oligarquías y grupos de poder blanco-mestizo, han empezado a luchar en algunos hechos, fuera de las demandas y luchas indio originario campesinos populares afros, pero existen profundas fisuras dentro de estos grupos en esta lucha. Hay una profunda crisis elitaria, dado que están perdiendo privilegios de casta y de poder, en particular los grupos bicentenarios. Incluso carecen de un proyecto alterno socialmente aceptable a la posibilidad de un horizonte plural y antineocolonial. No tienen líderes que sean capaces de re-orientar la histórica derrota que sufren. 
Al mismo tiempo, sin embargo, los movimientos sociales, los líderes indios originarios campesinos, también parecen perder en ciertos momentos el horizonte histórico de una verdadera refundación del Estado y de las instituciones públicas y privadas. La autonomía de lucha social construida largamente parece no estar tan intacta, por efecto de la cooptación y la prebenda. Si esto se profundiza, sería catastrófico. En particular, si no se consigue realmente una transformación de las condiciones de dominación política y de explotación económica que sufre la mayoría nacional, los indios originarios. Incluso existe el peligro de que esta mayoría quede reducida a una "nueva minoría", porque lo indio originario campesino está siendo conceptualizado y operativizado según la antropología colonialista que lo percibe fuera de las grandes ciudades, viviendo en lugares alejados y en condiciones descritas como las de los darwinistas sociales del siglo XIX y XX. Cuando, en realidad, lo indio originario campesino constituye y ha construido grandes ciudades, y también, es parte de la población mayoritaria en el exterior; en resumen, es el cuerpo mismo de la nación plural.

El horizonte plural del Estado y de la Sociedad es, entonces, un gran desafío. Por ello, en esto será de mucha importancia la acción efectiva de los actores históricos en la lógica fundacional para no ser enajenados de sus propios marcos de lucha, de los símbolos contestatarios, y para no ser objeto de un simple uso simbólico. En lo concreto, se trata de construir un país antioligárquico y anti-neocolonial y con la participación de todos los sectores sociales. Ya que, pese a la derrota histórica de los grupos de poder bicentenario, éstos todavía están plenamente vigentes. Incluso existe la posibilidad de que se apropien de una parte del territorio nacional, los departamentos del Oriente o la Amazonía. O que en estos territorios se establezcan medidas de racismo al igual que hicieron los afrikáners o los bóers ${ }^{11}$ en la Sudáfrica anterior a 1992 (Rojo 1993).

Por esto, la nueva la Constitución es parte de esta lucha. Por un lado, está la posibilidad histórica de refundar efectivamente un nuevo Estado y una nueva Sociedad y, por otro, de ser parte de una disminución histórica en los propios términos de la lucha social. Morir para no lograr nada, o haber logrado poco. Los indicios de la facticidad neocolonial se mantienen todavía

${ }^{11}$ Estos eran migrantes, o mejor dicho, colonizadores holandeses, franceses e ingleses que se establecieron en Sudáfrica desde el siglo XV hasta el XX y se convirtieron en los grupos dominantes frente a una gran mayoría de población negra, de cerca de 29 millones para 1992. 
vigentes en la toma de decisiones, la rutina estatal, o más propiamente, en la administración pública y los medios de comunicación (estatal y privada). Circulan lógicas expropiantes del poder de la gente, hecho que contradice el principio de un Estado plurinacional y de un horizonte de descolonización. ¿O es que acaso estamos asistiendo a una falsa descolonización, como dijera Frantz Fanon? (2003). La descolonización significa cambiar de un sistema neocolonial a otro sistema social más plural y horizontal. Aunque, según el mismo autor, esto es doloroso y nosotros diríamos que lo es tanto para el neocolonizado como para el neocolonialista. Es un cambio real, fáctico, de un sistema civilizatorio a otro sistema civilizatorio.

Desde la visión indio originaria campesina, la pregunta urticante en este caso es: ¿cómo puede el sistema comunal de la política y de la economía ser parte efectiva de un "nuevo" Estado? Este es un verdadero desafío histórico, práctico y filosófico. Este es un momento de tránsito histórico entre uno y otro sistema y, como tal, es parte vital de la lucha por el poder.

\section{Bibliografía citada}

AUGÉ, Marc. 2005. Los 'no lugares', espacios del anonimato. Una antropología de la sobremodernidad. Barcelona: Gedisa.

ARNADE, Charles W. 2004. La dramática insurgencia de Bolivia. La Paz: Juventud.

BARRIOS S., Franz X. 2008. Hacia un pacto territorial en Bolivia. Conflictos, conceptos, consensos en torno a las autonomías. La Paz: PNUD.

---. 2004. La administración pública en la Constitución boliviana. Diagnóstico crítico. La Paz: Unidad de Coordinación de la Asamblea Constituyente, Embajada de España en Bolivia.

CORRIGAN, Philipp y Derek Sayer. 2007. "La formación del Estado inglés como revolución cultural”. Antropología del Estado. Dominación y prácticas contestarías en América Latina. María Lagos y Pamela Calla, comps. La Paz: PNUD. 39-116.

FANON, Frantz. 2003. Los condenados de la tierra. México: Fondo de Cultura Económica.

JAUREGUI, Maggie y otros. 2003. Malestar social y administración pública. Abuso de poder, discriminación y corrupción en Santa Cruz de la Sierra. La Paz: Facultad de Humanidades UAGRM, CEDURE, PIEB. 
LEY ELECTORAL TRANSITORIA (Régimen Electoral Transitorio) 2009.

[http://www.cepal.org/oig/doc/Bol_Ley4021_2009.pdf] página descargada el 20 de diciembre 2013.

MAMANI RAMIREZ, Pablo. 2012. Wiphalas y fusiles. Poder comunal y levantamiento aymara de Achakachi-Omasuyus (2000- 2001). La Paz: Revista Willka, Sol de Paz Pachakuti, Flacso-Ecuador.

---. et al. 2011. “¿Por qué pensar fuera de los marcos de izquierda y derecha? Reflexión crítica desde Qullasuyu/Bolivia”. Palabras para tejernos, resistir y transformar en la época que estamos viviendo, Cochabamba: Textos Rebeldes. 171-202.

---. 2010a. “El contrapoder y el poder. Lo indígena-popular y lo liberal moderno en Bolivia". Socialismo, capitalismo y movimientos sociales. Alicia Solis de Alba et al, coords. México DF: UAM, Iztapalapa. 283-294.

---. 2010b. El rugir de las mutitudes: microgobiernos barriales. La Paz: La Mirada Salvaje.

---. 2008. Reconstitución y cartografía del poder del ayllu. Experiencia organizativa y lucha del movimiento de los ayllus en Qullasuyu/Bolivia. La Paz: IDIS, UMSA.

---. et al. 2006 "Microgobiernos barriales y su poder. Guerra del gas en El AltoBolivia". Sujetos y formas de la transformación política en Bolivia. La Paz: Tercera Piel.

---. 2005. Geopolíticas indígenas. El Alto: CADES.

---. 2004. El rugir de las multitudes. La fuerza de los levantamientos indígenas en Bolivia/Qullasuyu. La Paz: Aruwiyiri, Yachaywasi.

PATZI, Félix. 2004. Sistema comunal. Una propuesta alternativa al sistema liberal. La Paz: CEA.

PAZ, Danilo. 2004. "Medio siglo de reforma agraria boliviana". Temas Sociales 25. 183-188.

PAZ, Eduardo. 2007. Documento: carpeta curricular del segundo diplomado en gestión pública intercultural. La Paz: SNAP.

PNUD (Programa de las Naciones Unidas para el Desarrollo). 2007. Informe nacional sobre desarrollo humano 2007: El estado del Estado en Bolivia. La Paz: PNUD.

PRADA, Raúl. 2007. "Articulaciones de la complejidad”. La transformación pluralista del estado. Álvaro García Linera y otros, eds. La Paz: Muela del Diablo. 199-270. 
ROJO, Alfonso. 1993. La odisea de la tribu blanca. Sudáfrica en la encrucijada después del "apartheid", enfrentada al reto de superar el racismo sin caer en el caos. Barcelona: Planeta.

STAVENHAGEN, Rodolfo. 2009. Promoción y protección de todos los derechos humanos, civiles, políticos, económicos, sociales y culturales, incluido el derecho al desarrollo. Informe del Relator Especial sobre la situación de los derechos humanos y las libertades fundamentales de los indígenas. Misión a Bolivia. Oficina del Alto Comisionado de las Naciones Unidas para los Derechos Humanos (OACNUDH). La Paz: Naciones Unidas.

VAN DIJK, Teun. 2003. Racismo y discurso de las élites. Barcelona: Gedisa.

YAMPARA, Simón. 2001. El ayllu y la territorialidad en los Andes. Una aproximación a Chambi Grande. Altu Pata: UPEA, Inti Andino.

\section{(oc) BY-NC-ND}

ULLS
This work is licensed under a Creative Commons AttributionNoncommercial-No Derivative Works 3.0 United States License.

This journal is published by the University Library System of the University of Pittsburgh as part of its D-Scribe Digital Publishing Program, and is cosponsored by the University of Pittsburgh Press. 